\title{
Study on Effect of Welding Speed on Micro Structure and Mechanical Properties of Pulsed Current Micro Plasma Arc Welded Inconel 625 Sheets
}

\author{
Chalamalasetti Srinivasa Rao ${ }^{1}$, Kondapalli Siva Prasad ${ }^{2 *}$, Damera Nageswara Rao ${ }^{3}$ \\ ${ }^{1}$ Department of Mechanical Engineering, AU College of Engineering, Andhra University, Visakhapatnam, India \\ ${ }^{2}$ Department of Mechanical Engineering, Anil Neerukonda Institute of Technology \& Sciences, Visakhapatnam, India \\ ${ }^{3}$ Vice Chancellor, Centurion University of Technology \& Management, Odisha, India \\ Email: *kspanits@gmail.com
}

Received June 8, 2012; revised July 15, 2012; accepted July 30, 2012

\begin{abstract}
Nickel alloys had gathered wide acceptance in the fabrication of components which require high temperature resistance and corrosion resistance, such as metallic bellows used in expansion joints used in aircraft, aerospace and petroleum industry. Micro Plasma Arc Welding (MPAW) is one of the important arc welding processes commonly using in fabriccation of Nickel alloys. In the present paper welding of Inconel 625 sheets using pulsed current micro plasma arc welding was discussed. The paper mainly focuses on studying the weld quality characteristics like weld pool geometry parameters, microstructure, grain size, hardness and tensile properties of Pulsed Current Micro Plasma Arc Welded Inconel 625 sheets at different welding speeds. Results reveals that at a welding speed of $260 \mathrm{~mm} / \mathrm{minute}$ better weld quality characteristics can be obtained.
\end{abstract}

Keywords: Pulsed Current Micro Plasma Arc Welding; Inconel 625; Grain Size; Hardness; Tensile Properties

\section{Introduction}

The plasma welding process was introduced to the welding industry in 1964 as a method of bringing better control to the arc welding process in lower current ranges. Today, plasma retains the original advantages it brought to the industry by providing an advanced level of control and accuracy to produce high quality welds in both miniature and pre precision applications and to provide long electrode life for high production requirements at all levels of amperage. Plasma welding is equally suited to manual and automatic applications. It is used in a variety of joining operations ranging from welding of miniature components to seam welding to high volume production welding and many others.

During welding of thin sheets by conventional arc welding processes, which offer high heat input has various problems such as burn through or melt trough, distortion, porosity, buckling warping \& twisting of welded sheets, grain coarsening, evaporation of useful elements present in coating of the sheets, joint gap variation during welding, fume generation form coated sheets etc. Micro Plasma arc Welding (MPAW) is a good process for joining thin sheet, but it suffers high equipment cost compared to Gas Tungsten Arc Welding (GTAW). However

\footnotetext{
${ }^{*}$ Corresponding author.
}

it is more economical when compare with Laser Beam welding and Electron Beam Welding processes.

Pulsed current MPAW involves cycling the welding current at selected regular frequency. The maximum current is selected to give adequate penetration and bead contour, while the minimum is set at a level sufficient to maintain a stable arc $[1,2]$. This permits arc energy to be used effectively to fuse a spot of controlled dimensions in a short time producing the weld as a series of overlapping nuggets. By contrast, in constant current welding, the heat required to melt the base material is supplied only during the peak current pulses allowing the heat to dissipate into the base material leading to narrower Heat Affected Zone (HAZ). Advantages include improved bead contours, greater tolerance to heat sink variations, lower heat input requirements, reduced residual stresses and distortion, refinement of fusion zone microstructure and reduced width of HAZ.

From the earlier works reported on Inconel 625 [3-5] it is understood that selection of welding process parameters play a vital role in obtaining the desired weld quality. Hence, an attempt is made to study the welding quality characteristics. The present paper focuses on studying the weld quality characteristics like weld pool geometry parameters, microstructure, grain size, hardness and tensile properties of Pulsed Current Micro Plasma Arc Welded 
Inconel 625 sheets.

\section{Experimental Procedure}

Inconel 625 sheets of $100 \times 150 \times 0.25 \mathrm{~mm}$ are welded autogenously with square butt joint without edge preparation. The chemical composition of Inconel 625 is given in Table 1. High purity argon gas (99.99\%) is used as a shielding gas and a trailing gas right after welding to prevent absorption of oxygen and nitrogen from the atmosphere. The welding has been carried out under the welding conditions presented in Table 2 . There are many influential process parameters which effect the weld quality characteristics of Pulsed Current MPAW process like peak current, back current, pulse rate, pulse width, flow rate of shielding gas, flow rate of purging gas, flow rate of plasma gas, welding speed etc. From the earlier works [6-9] carried out on Pulsed Current MPAW it was understood that the peak current, back current, pulse rate and pulse width are the dominating parameters which effect the weld quality characteristics. The values of process parameters used in this study are the optimal values obtained from our earlier papers [3-5]. Hence peak current, back current, pulse rate and pulse width are chosen and their values are presented in Table 3 .

Table 1. Chemical composition of INCONEL 625 (weight \%).

\begin{tabular}{ccccccccc}
\hline $\mathrm{C}$ & $\mathrm{Mn}$ & $\mathrm{P}$ & $\mathrm{S}$ & $\mathrm{Si}$ & $\mathrm{Cr}$ & $\mathrm{Ni}$ \\
\hline 0.0300 & 0.0800 & 0.0050 & 0.0004 & 0.1200 & 20.8900 & 61.6000 \\
$\mathrm{Al}$ & $\mathrm{Mo}$ & $\mathrm{Cb}$ & $\mathrm{Ta}$ & $\mathrm{Ti}$ & $\mathrm{N}$ & $\mathrm{Co}$ & $\mathrm{Fe}$ \\
0.1700 & 8.4900 & 3.4400 & 0.0050 & 0.1800 & 0.0100 & 0.1300 & 4.6700 \\
\hline
\end{tabular}

Table 2. Welding conditions.

\begin{tabular}{ll}
\hline Power source & $\begin{array}{l}\text { Secheron micro plasma arc machine } \\
\text { (model: PLASMAFIX 50E) }\end{array}$ \\
\hline Polarity & DCEN \\
Mode of operation & Pulse mode \\
Electrode & $2 \%$ thoriated tungsten electrode \\
Electrode diameter & 1 mm \\
Plasma gas & Argon \& hydrogen \\
Plasma gas flow rate & 6 Lpm \\
Shielding gas & Argon \\
Shielding gas flow rate & 0.4 Lpm \\
Purging gas & Argon \\
Purging gas flow rate & $0.4 \mathrm{Lpm}$ \\
Copper nozzle diameter & $1 \mathrm{~mm}$ \\
Nozzle to plate distance & $1 \mathrm{~mm}$ \\
Welding speed & $260 \mathrm{~mm} /$ min \\
Torch Position & Vertical \\
Operation type & Automatic \\
\hline
\end{tabular}

Table 3. Important weld parameters.

\begin{tabular}{cccc}
\hline Serial No. & Input factor & Units & Value \\
\hline 1 & Peak current & Amperes & 7 \\
2 & Back current & Amperes & 4 \\
3 & Pulse rate & Pulses/second & 40 \\
4 & Pulse width & $\%$ & 50 \\
\hline
\end{tabular}

\subsection{Measurement of Weld Bead Geometry}

Sample preparation and mounting was done as per ASTM E 3-1 standard. The samples were cut from the welded specimens and mounting using Bakelite powder. After standard metallurgical polishing process, aqua regia is used as the etchant to reveal weld bead geometry. The weld pool geometries were measured using Metallurgical Microscope, Make: Dewinter Technologie, Model No. DMI-CROWN-II. A typical weld bead geometry is shown in Figure 1.The measured values of weld pool geometry are presented in Table 4.

Figures 2(a)-(d) indicate the back surface of the welded joint at welding speeds of 150, 200, $260 \& 300$ $\mathrm{mm} /$ minute respectively.

\subsection{Microstructure Measurement}

For Microstructure measurement ASTM E 407 was followed for Etching along with ASM Metal Hand Book, Volume 9. For revealing the Microstructure the weld samples are mounted using Bakelite and polishing was done according to standard Metallurgical procedure. Aqua Regia was used as an etchant. For revealing the Microstructure, Electrolytic Etching was done. The Microstructure was measured using Metallurgical Microscope at a magnification of $100 \times$. Figures 3(a)-(d) indicates the microstructures at welding speeds of 150, 200, $260 \& 300 \mathrm{~mm} /$ minute respectively. The left portion in the Figures 3(a)-(d) indicates weld fusion zone ad right portion indicates Heat Affected Zone (HAZ).

\subsection{Grain Size Measurement}

In order to reveal the grains, polishing was done according to standard Metallurgical procedure and Etching was done as per ASTM E407. Electrolytic was done using Aqua Regia for about 1 minute. Scanning Electron Microscope, Make: INCA Penta FETx3, Model: 7573 as shown in Figure 4 is used to measure the fusion zone grain size and parent metal. Figures 5(a)-(d) indicates the fusion zone grain size at welding speeds of 150, 200, $260 \& 300 \mathrm{~mm} / \mathrm{minute}$ respectively. As the grains in some parts of the weld fusion zone are elongated and uneven, an average value was reported by measuring grain size at different locations in the fusion zone of each sample. 
Table 4. Variation of hardness values across the weld joint at $0.3 \mathrm{~mm}$ interval.

\begin{tabular}{|c|c|c|c|c|c|c|c|c|c|}
\hline \multirow{3}{*}{$\begin{array}{l}\text { Elding speed } \\
\text { (mm/minute) }\end{array}$} & \multicolumn{9}{|c|}{ Hardness values in VHN at different locations on the weld joint } \\
\hline & \multicolumn{2}{|c|}{ HAZ zone } & \multicolumn{5}{|c|}{ Fusion zone } & \multicolumn{2}{|c|}{ HAZ zone } \\
\hline & 1 & 2 & 3 & 4 & 5 & 6 & 7 & 8 & 9 \\
\hline 150 & 260.7 & 258.4 & 229.3 & 242.0 & 241.9 & 248.8 & 250.8 & 249.3 & 255.2 \\
\hline 200 & 242.4 & 255.6 & 254.6 & 238.2 & 231.9 & 240.0 & 255.0 & 240.1 & 234.2 \\
\hline 260 & 247.8 & 255.5 & 242.3 & 248.1 & 262.4 & 249.5 & 260.6 & 256.6 & 244.0 \\
\hline 300 & 232.2 & 238.5 & 250.1 & 239.9 & 253.9 & 236.3 & 255.0 & 238.4 & 226.5 \\
\hline
\end{tabular}

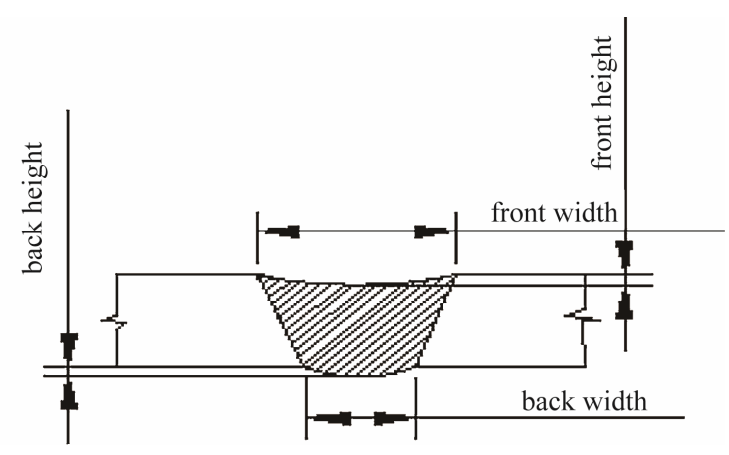

Figure 1. Typical weld bead geometry.

\subsection{Measurement of Vickers Micro Hardness}

Vickers Micro hardness was done as per ASTM E384. The samples were cut from the welded specimens and Vickers Micro Hardness values across the weld joint at an interval of $0.3 \mathrm{~mm}$ using Digital Micro Hardness testing Machine, make METSUZAWA CO LTD, JAPAN, Model No: MMT-X7 as shown in Figure 6.

In the Table 4 points 1, 2, 8, 9 indicates at Heat Affected Zone (HAZ) and the points 3, 4, 5, 6, 7 indicate at Fusion Zone (FZ). The location of the hardness measuring points is shown in Figure 7. The variation of hardness across the weld is shown in Figure 8.

From Table 4 and Figure 8 it understood that hardness at centre of FZ is less and it keeps on increasing towards HAZ.

\subsection{Measurement of Ultimate Tensile Strength}

Three transverse tensile specimens are prepared as per ASTM E8M-04 guidelines and the specimens after wire cut Electro Discharge Machining are shown in Figure 9 and 10. Tensile tests are carried out in $100 \mathrm{kN}$ computer controlled Universal Testing Machine (ZENON, Model No: WDW-100) as shown in Figure 11. The specimen is loaded at a rate of $1.5 \mathrm{kN} / \mathrm{min}$ as per ASTM specifications, so that the tensile specimens undergo deformation. From the stress strain curve, the yield and ultimate tensile strength of the weld joints is evaluated and the average of three results is presented in Table 5.

\section{Results \& Discussions}

\subsection{Weld Pool Geometry}

From Table 5 and from Figures 2(a)-(d) it is noticed that at the welding speed of $150 \mathrm{~mm} /$ minute over melting of base metal was noticed and when the welding speed of $300 \mathrm{~mm} /$ minute there is improper fusion of the base metal. At the welding speed of around $260 \mathrm{~mm} / \mathrm{min}$ optimum weld pool geometry parameters are obtained.

\subsection{Fusion Zone Grain Size}

The variation of fusion zone grain size with respect to welding speed was presented in Figure 12. It is noticed that the grain size decreased up to a welding speed of 260 $\mathrm{mm} /$ minute and there after increased. This is due to improper fusion of base metal.

\subsection{Fusion Zone Hardness}

The variation of fusion zone hardness with respect to welding speed was presented in Figure 13. It is noticed that the hardness increases gradually up to $252.58 \mathrm{VHN}$ at welding speed of $260 \mathrm{~mm} /$ minute and there after decreases to $247.04 \mathrm{VHN}$, when the welding speed is 300 $\mathrm{mm} /$ minute.

\subsection{Ultimate Tensile Strength}

The variation of ultimate tensile strength with respect to welding speed was presented in Figure 14. It is noticed that the ultimate tensile strength increases gradually up to $857 \mathrm{MPa}$ at welding speed of $260 \mathrm{~mm} /$ minute and there after decreases to $837 \mathrm{MPa}$, when the welding speed is $300 \mathrm{~mm} /$ minute.

\section{Conclusion}

Inconel 625 sheets are successfully welded using pulsed current MPAW process at different welding speeds. From the experiments performed, it is revealed that sound weld pool geometry is obtained at the welding speed of $260 \mathrm{~mm} /$ minute. Fusion zone grain size decreased from welding speed of $150 \mathrm{~mm} /$ minute to 300 


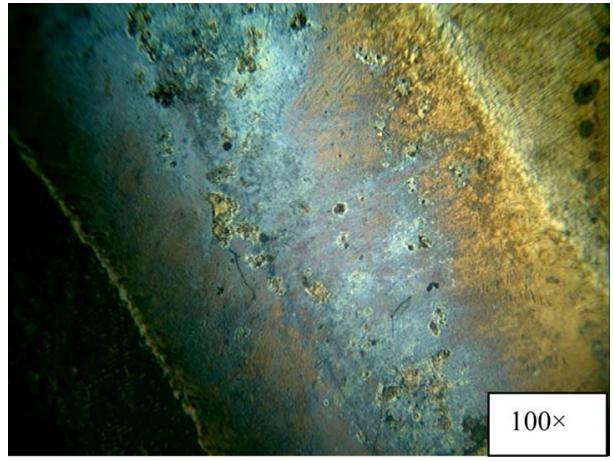

(a)

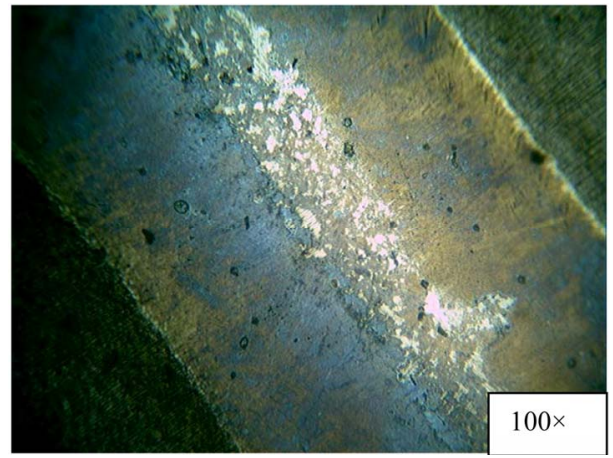

(c)

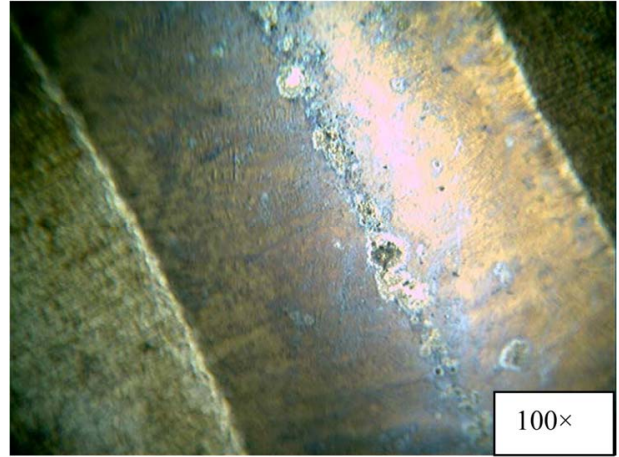

(b)

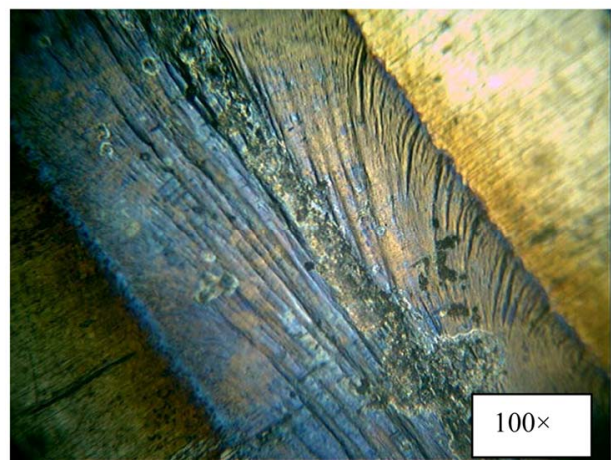

(d)

Figure 2. (a) welding speed of $150 \mathrm{~mm} /$ minute; (b) welding speed of $200 \mathrm{~mm} / \mathrm{minute}$; (c) welding speed of $260 \mathrm{~mm} / \mathrm{minute}$; (d) welding speed of $300 \mathrm{~mm} / \mathrm{minute}$.

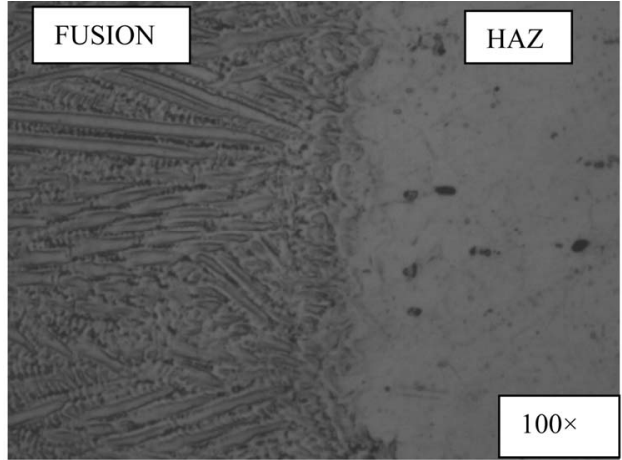

(a)

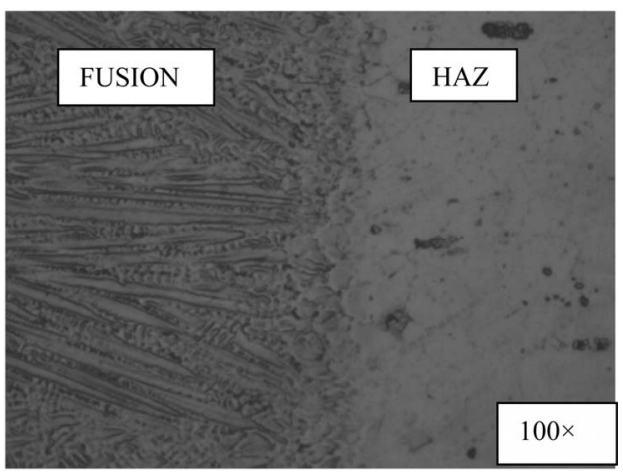

(c)

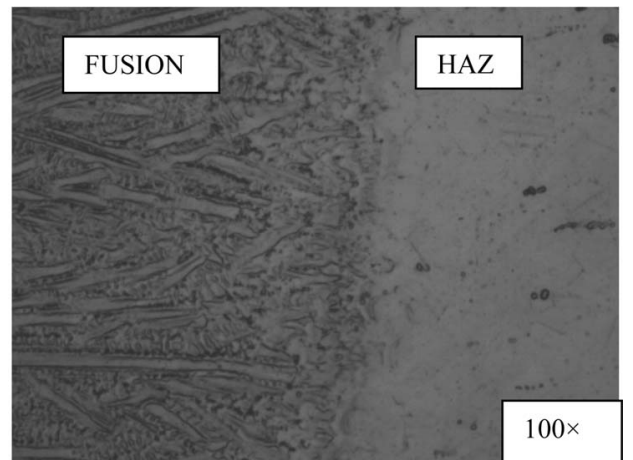

(b)

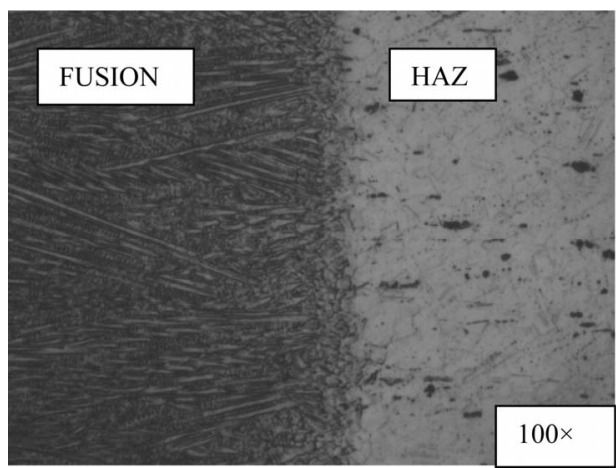

(d)

Figure 3. (a) welding speed of $150 \mathrm{~mm} / \mathrm{minute}$; (b) welding speed of $200 \mathrm{~mm} / \mathrm{minute}$; (c) welding speed of $260 \mathrm{~mm} / \mathrm{minute}$; (d) welding speed of $300 \mathrm{~mm} / \mathrm{minute}$. 


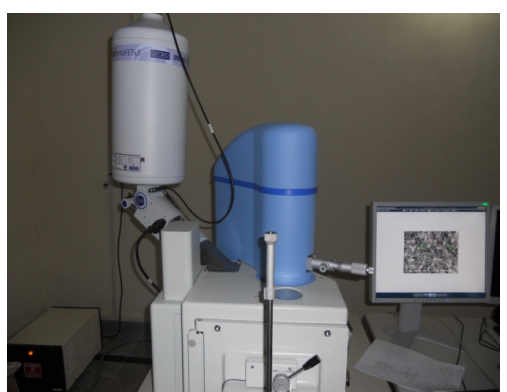

Figure 4. Scanning electron microscope.

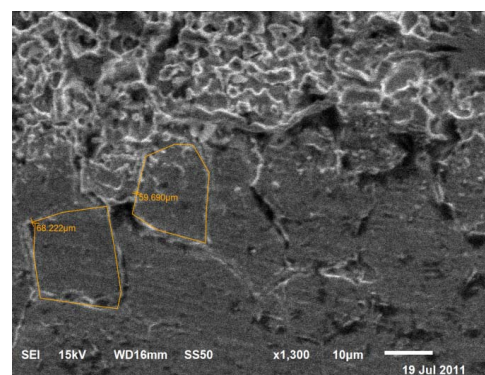

(a)

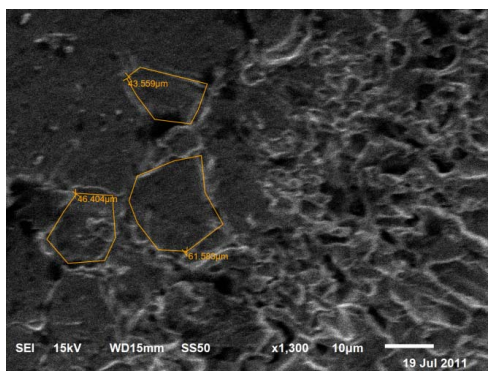

(b)

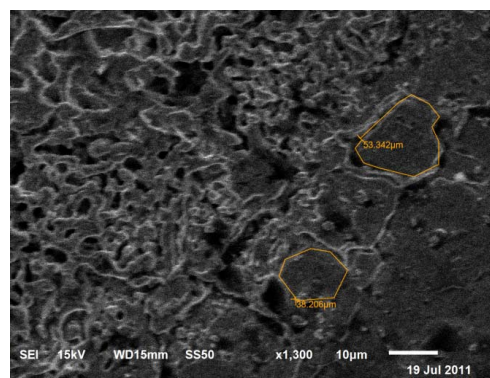

(c)

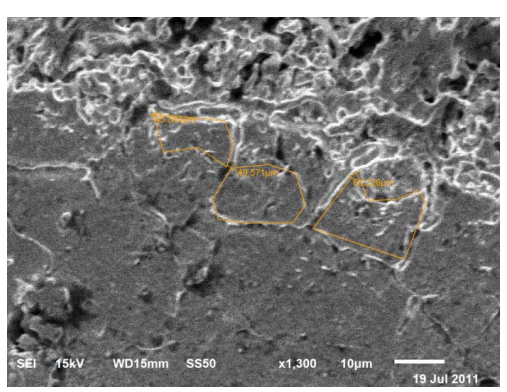

(d)

Figure 5. (a) Welding Speed of $150 \mathrm{~mm} /$ minute; (b) Welding speed of $200 \mathrm{~mm} / \mathrm{minute}$; (c) Welding speed of $260 \mathrm{~mm} / \mathrm{mi}$ nute; (d) Welding speed of $300 \mathrm{~mm} /$ minute.

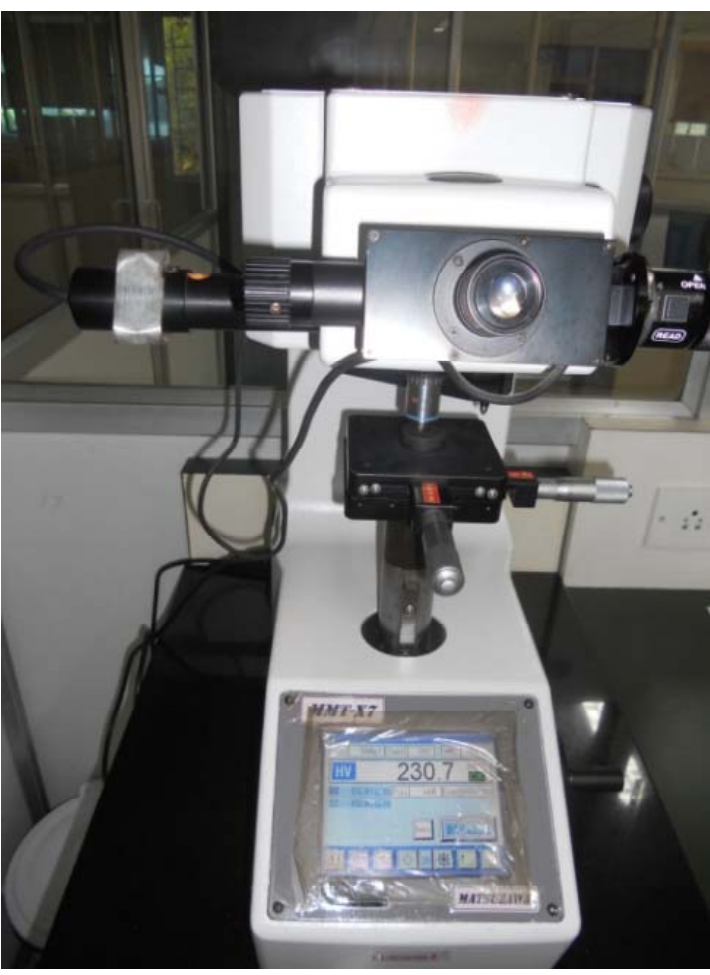

Figure 6. Vickers micro hardness tester.

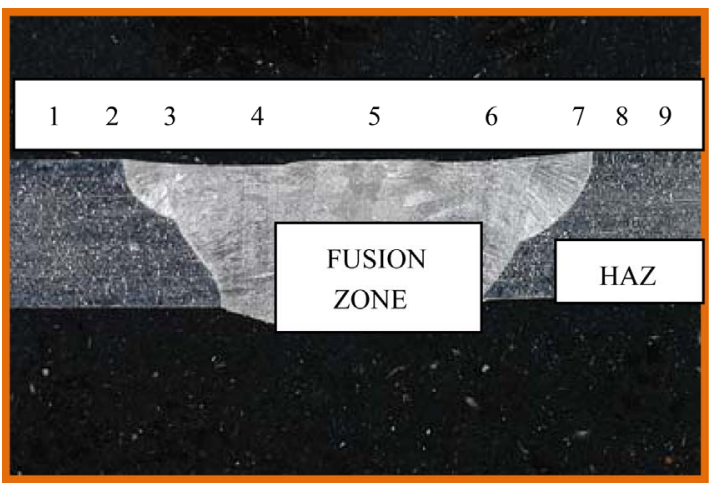

Figure 7. Location of hardness measuring points on the weld joint.

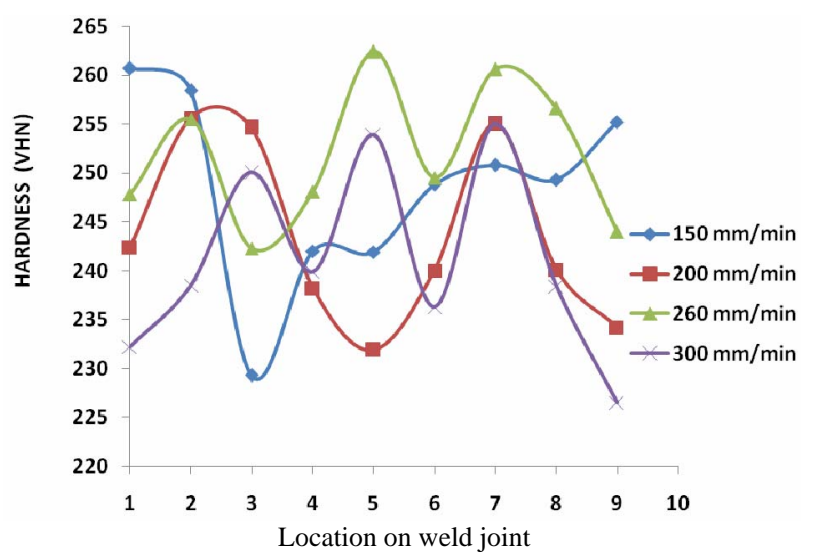

Figure 8. Variation of hardness across the weld. 


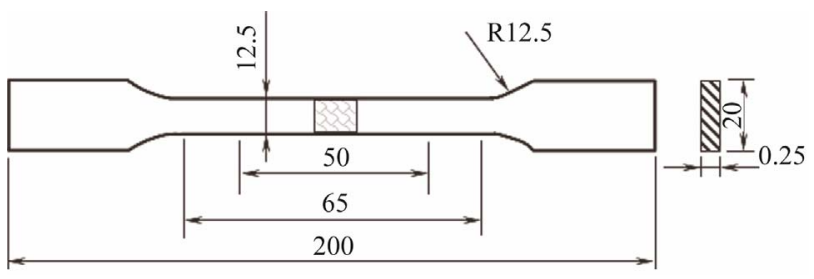

Figure 9. Schematic diagram of tensile specimen as per ASTM E8.

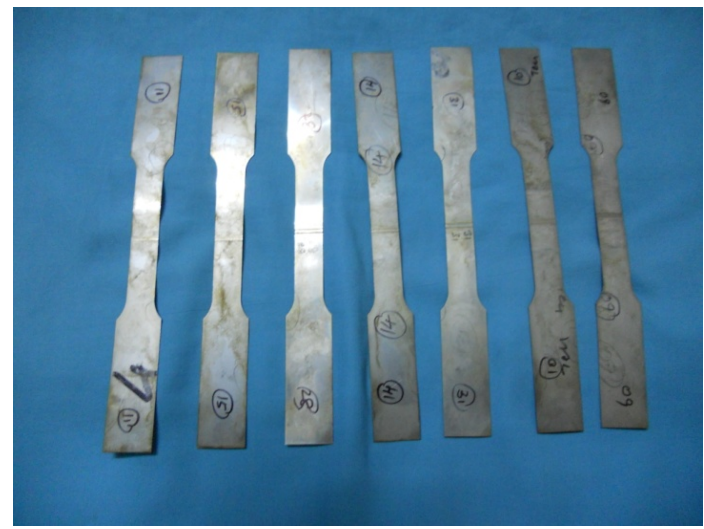

Figure 10. Tensile specimens of inconel 625 welded joints.

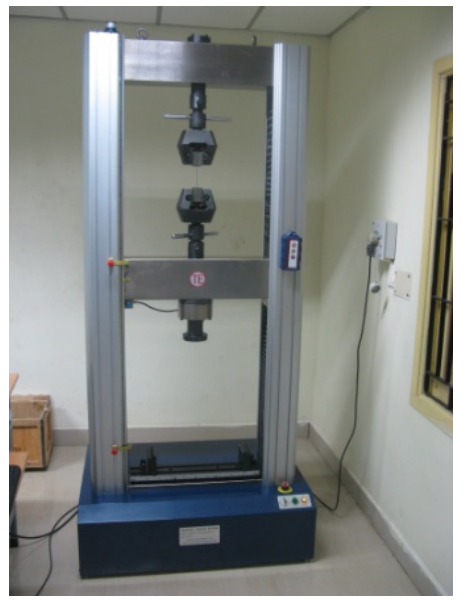

Figure 11. Universal testing machine.

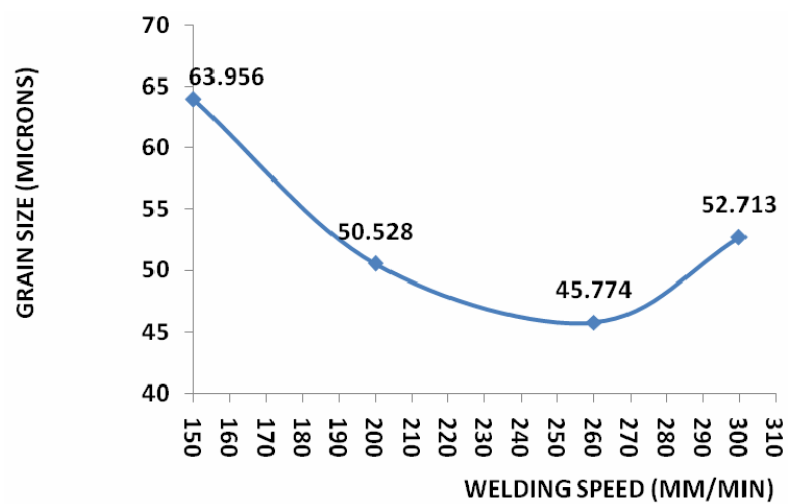

Figure 12. Variation of fusion zone grain size.



Figure 13. Variation of fusion zone hardness.

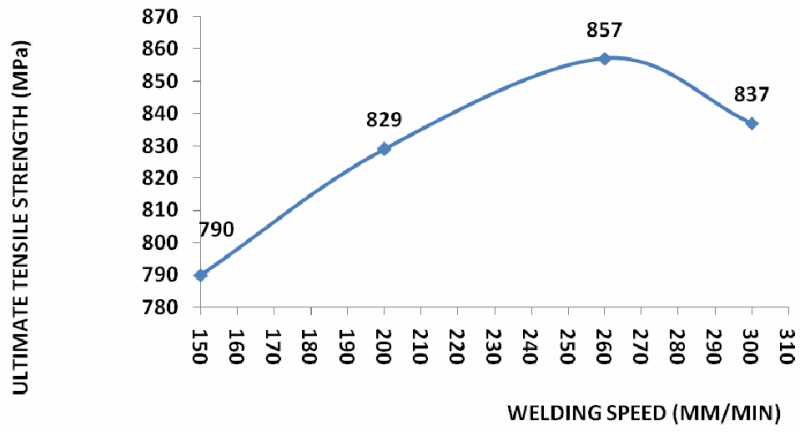

Figure 14. Variation of ultimate tensile strength.

Table 5. Comparison of weld quality characteristics.

\begin{tabular}{|c|c|c|c|c|c|c|c|}
\hline \multirow{2}{*}{$\begin{array}{l}\text { Welding Speed } \\
\text { (mm/minute) }\end{array}$} & \multicolumn{4}{|c|}{ Weld pool Geometry } & \multirow{2}{*}{$\begin{array}{l}\text { Fusion Zone grain } \\
\text { size (Microns) }\end{array}$} & \multirow{2}{*}{$\begin{array}{l}\text { Fusion Zone } \\
\text { hardness } \\
\text { (VHN) }\end{array}$} & \multirow{2}{*}{$\begin{array}{l}\text { Ultimate } \\
\text { Strength } \\
\text { (MPa) }\end{array}$} \\
\hline & Front Width & Back Width & Front Height & Back Height & & & \\
\hline 150 & 1.231 & 1.171 & 0.0458 & 0.0358 & 63.956 & 242.56 & 790 \\
\hline 200 & 1.253 & 1.188 & 0.0475 & 0.0376 & 50.528 & 243.94 & 829 \\
\hline 260 & 1.270 & 1.202 & 0.0456 & 0.0356 & 45.774 & 252.58 & 857 \\
\hline 300 & 1.153 & 1.075 & 0.0470 & 0.0366 & 52.713 & 247.04 & 837 \\
\hline
\end{tabular}

$\mathrm{mm} / \mathrm{minute}$, where as fusion zone hardness and ultimate tensile strength increased with welding speed up to 260 $\mathrm{mm} / \mathrm{minute}$ and thereafter decreased. From the results on various weld quality characteristics tests, it is understood that at the welding speed of $260 \mathrm{~mm} /$ minute, optimal weld quality characteristics are obtained. 


\section{Acknowledgments}

The authors would like to thank Shri. R.Gopla Krishnan, Director, M/s Metallic Bellows (I) Pvt Ltd, Chennai for his support to carry out experimentation work.

\section{REFERENCES}

[1] M. Balasubramanian, V. Jayabalan and V. Balasubramanian, "Effect of Process Parameters of Pulsed Current Tungsten Inert Gas Welding on Weld Pool Geometry of Titanium Welds," Acta Metallurgica Sinica (English Letters), Vol. 23, No. 4, 2010, pp. 312-320.

[2] B. Balasubramanian, V. Jayabalan and V. Balasubramanian, "Optimizing the Pulsed Current Gas Tungsten Arc Welding Parameters," Journal of Materials Science \& Technology, Vol. 22, No. 6, 2006, pp. 821-825.

[3] K. S. Prasad, C. S. Rao and D. N. Rao, “Optimizing Pulsed Current Micro Plasma Arc Welding Parameters to Maximize Ultimate Tensile Strength of Inconel 625 Nickel Alloy Using Response Surface Method,” International Journal of Engineering, Science and Technology, Vol. 3, No. 6, 2011, pp. 226-236.

[4] K. S. Prasad, C. S. Rao and D. N. Rao, “Optimizing Fusion Zone Grain Size and Ultimate Tensile Strength of Pulsed Current Micro Plasma Arc Welded Inconel 625 Alloy Sheets Using Hooke \& Jeeves Method,” International Transaction Journal of Engineering, Management, \& Applied Sciences \& Technologies, Vol. 3, No. 1, 2012, pp. 87-100.

[5] K. S. Prasad, C. S. Rao and D. N. Rao, "Effect of Process Parameters of Pulsed Current Micro Plasma Arc Welding on Weld Pool Geometry of Inconel 625 Welds,” Kovove Materialy-Metallic Materials, Vol. 50, No. 3, 2012, pp. 153-159 (in press).

[6] R. Manti, D. K. Dwivedi and A. Agarwal, "Microstructure and Hardness of Al-Mg-Si Weldments Produced by Pulse GTA Welding," The International Journal of Advanced Manufacturing Technology, Vol. 36, No. 3-4, 2008, pp. 263-269. doi:10.1007/s00170-006-0849-z

[7] T. S. kumar, V. Balasubramanian, S. Babu and M. Y. Sanavullah, "Effect of Pulsed Current GTA Welding Parameters on the Fusion Zone Microstructure of AA 6061 Aluminium Alloy, Metal and Materials International, Vol. 13, No. 4, 2007, pp. 345-351.

[8] N. Karunakaran and V. Balasubramanian, "Effect of Pulsed Current on Temperature Distribution, Weld Bead Profiles and Characteristics of Gas Tungsten Arc Welede Aluminium Alloy Joints," Transactions of Nonferrous Metals Society of China, Vol. 21, No. 2, 2011, pp. 278286. doi:10.1016/S1003-6326(11)60710-3

[9] G. Padmanaban and V. Balasubramanian, "Influences of Pulsed Current Parameters on Mechanical and Metallurgical Properties of Gas Tungsten Arc Welede AZ31B Magnesium Alloy,” Metals and Materials International, Vol. 17, No. 4, 2011, pp. 679-687. doi:10.1007/s12540-011-0826-4 